\title{
SHARP INEQUALITIES FOR TRIGONOMETRIC AND HYPERBOLIC FUNCTIONS
}

\section{Chao-Ping Chen and József Sándor}

Abstract. We establish several sharp inequalities for trigonometric and hyperbolic functions. Our results sharpen some known inequalities. Mathematics subject classification (2010): 26D05, 26D07. Keywords and phrases: Inequalities, trigonometric functions, hyperbolic functions.

\section{REFERENCES}

[1] M. Abramowitz and I. A. Stegun (EDS), Handbook of Mathematical Functions with Formulas, Graphs, and Mathematical Tables, National Bureau of Standards, Applied Mathematics Series 55, 4th printing, Washington, 1965, 1972.

[2] G. D. Anderson, M. K. Vamanamurthy And M. Vuorinen, Inequalities for quasiconformal mappings in space, Pacific J. Math. 160 (1993), 1-18.

[3] G. D. Anderson, S.-L. Qiu, M. K. Vamanamurthy and M. Vuorinen, Generalized elliptic integral and modular equations, Pacific J. Math. 192 (2000), 1-37.

[4] G. D. Anderson, M. K. Vamanamurthy and M. Vuorinen, Conformal Invariants, Inequalities, and Quasiconformal Maps, New York, 1997.

[5] M. Becker AND E. L. STRAK, On a hierarchy of quolynomial inequalities for tanx, Univ. Beograd. Publ. Elektrotehn. Fak. Ser. Mat. Fiz. No. 602-633 (1978), 133-138.

[6] C.-P. Chen And W.-S. Cheung, Sharp Cusa and Becker-Stark inequalities, J. Inequal. Appl. 2011: 136 (2011), doi:10.1186/1029-242X-2011-136.

[7] J. S. Frame, Some trigonometric, hyperbolic and elliptic approximations, Amer. Math. Monthly 61 (1954), 623-626.

[8] C. Huygens, Oeuvres Completes 1888-1940, Société Hollondaise des Science, Haga.

[9] B. J. MALEŠEVIĆ, One method for proving inequalities by computer, J. Ineq. Appl. 2007, Article ID 78691.

[10] B. Malešević, M. MAKRAgić AND B. BANJAC, Some notes on a method for proving inequalities by computer, http://arxiv.org/abs/math/0701020.

[11] C. Mortici, The natural approach of Wilker-Cusa-Huygens inequalities, Math. Inequal. Appl. 14 (2011), 535-541.

[12] E. Neuman And J. SÁNDOR, On some inequalities involving trigonometric and hyperbolic functions with emphasis on the Cusa-Huygens, Wilker, and Huygens inequalities, Math. Inequal. Appl. 13 (2010), 715-723.

[13] S. Ponnusamy And M. Vuorinen, Asymptotic expansions and inequalities for hypergeometric functions, Mathematika 44 (1997), 278-301.

[14] J. SANDOR AND M. Bencze, On Huygens' trigonometric inequality, RGMIA Res. Rep. Collection 8, 3 (2005), Article 14.

[15] L. ZHU, A source of inequalities for circular functions, Comput. Math. Appl. 58 (2009), 1998-2004.

[16] L. ZHu, Some new inequalities of the Huygens type, Comput. Math. Appl. 58 (2009), 1180-1182.

[17] L. ZHU AND J. K. HUA, Sharpening the Becker-Stark inequalities, J. Inequal. Appl. 2010, Article ID 931275 .

[18] L. ZHU, Sharp Becker-Stark-type inequalities for Bessel functions, J. Inequal. Appl. 2010, Article ID 838740 . 